will be enough. If she is annoyed by painful tlatus which does not yield to teaspoonful doses of the fluid extract of valerian, a flexible catheter should be carefully introduced into the rectum. On the seventh or eighth day I shall cut and remove every suture except the rectal one. On the morning of the ninth day four ounces of warm olive-oil will be slowly injected into the rectum, followed two hours later by a soapwater enema. Should hardened fæces over-distend the rectum the nurse must break them up either by her finger, a hair-pin, or the handle of a spoon. When the medicine has operated I will remove the last suture.

After the bowels have been thoroughly opened they should be again locked up for four or five days more, and then be daily kept open by a mild aperient. The patient should have her knees bound together, and stay in bed for at least two weeks, and for a week longer should not go out of her room. During this latter time she should walk about but little, and keep her knees close together. Should a fistulous opening remain, fuming nitric acid should be applied, and the sides should be coaptated with sutures.

DIVISION OF THE TENDO ACHILLIS IN FRACTURE OF THE LOWER THIRD OF THE FEMUR; A CASE OF T FRACTURE.

BY M. A. MORRIS, M. D. HARV., ChARLESTOWN.

IN fractures of the leg where there is a tendency of the superior end of the lower fragment to override the upper one, and in fractures and dislocations about the ankle-joint when it becomes difficult or impossible to place and retain the fractured parts in position, owing to contraction and rigidity of the muscles of the calf, division of the tendo Achillis has been recommended, and excellent results from that procedure have been reported. In fractures of the lower third of the femur, various methods have been adopted for correcting the tendency of the upper end of the lower fragment to tilt out of position and backwards into the popliteal space, such as flexing the limb and placing it on a double inclined plane, etc. It seems to be pretty generally conceded that treatment in the straight position gives the best results in fractures of the thigh, for if the limb be placed in the flexed position there is a greater liability to trouble from anchylosis, which results in so many cases of fracture, particularly when situated near the knee-joint; and, again, it is impossible to keep up a proper amount of extension in the flexed position. When the fracture is in the lower third of the bone and near the condyles, the upper end of the lower fragment is apt to be drawn backward, making it difficult and sometimes imposil le to keep the ends of the bones in apposition, as the writer has found from expe- 
rience. In one case, which was treated in the straight position by competent surgeons, tilting backward of the lower fragment took place, and the result was delayed union, with protracted confinement to bed, and a firm anchylosis which it required a long time to recover from.

Another case was also slow to recover, and when the splints were finally removed a large, irregular callus could be felt just above the popliteal space.

None of the authors, so far as we have been able to learn, recommend tenotomy of the tendo Achillis in such cases except Bryant, who says: " "I have taught this method for the last two years, but have had only one opportunity of testing its value." The case here reported seems to have been a proper one for the trial of this method.

The subject was a man aged forty, of delicate constitution, who had suffered in early life from a disease of the left knee-joint, which left the head of the tibia dislocated somewhat outwards and backwards on the condyles of the femur, but good use of the joint was regained. About four years ago he sustained a fracture of both bones of the same leg, which made it shorter than its fellow. Two years ago, while returning from his place of business, he fell on the icy sidewalk and fractured the femur of the same side. The bone was broken obliquely, the line of fracture extending upwards and backwards two and a half or three inches from its articular end. There was also a longitudinal fracture separating the condyles, which could be freely moved and felt to grate against each other; there was considerable shortening, but little swelling about the joint. The muscles of the thigh were soft and flabby, but notwithstanding this, when extension was made and the limb put in position, the upper ends of the lower fragments projected backwards, and could not be kept in position, on account of the traction of the gastrocnemius muscle.

Owing to the facts that this limb was already shorter than the other and that the patient would be very liable to have an anchylosed kneejoint, with considerable additional shortening, it was deemed best to place the limb in the straight position, and to divide the tendo Achillis, in order to paralyze the gastrocnemius. Under ether, the tendon was divided and the tendency to displacement overcome. The. limb was placed on a Macintyre's splint, and extension applied in the usual way by sticking-plaster straps bandaged to the leg and attached to a transverse foot-piece, from which swung a weight over a pulley at the foot of the bed. Counter-extension was made by elevating the foot of the bed; a cold-water dressing was applied over the joint, which began to swell a little, when an ice-bag was applied and the swelling subsided. At the end of eight weeks the patient was up, and a month later was able to move round, and soon could flex the knee almost to a right angle. The amount of shortening was about half an inch.

1 Pract. of Surgery, page 867. 
$\mathrm{T}$ fracture of the femur is a comparatively rare accident, and when it does occur is liable to lead to grave joint trouble and anchylosis. Hamilton says (page 431): "More fortunate results than these may, indeed, be hoped for, inasmuch as they have occasionally been noticed, but they cannot fairly be expected. In a majority of cases such accidents have demanded, either immediately or at a later period, amputation."

Bryant says (page 866): "These cases are serious on account of the joint complication, for some stiffness of the joint generally follows, but not always."

That we did not have more swelling of the joint in this case appears rather singular. The only reasons we should suggest for its absence are the following: the synovial membrane and parts about the joint may have been so lacerated as to allow the escape of the fluids secreted into the cellular tissue outside, which absorbed them as fast as formed; or the ice-bag may have prevented it.

It would appear to us there can be no objection to division of the tendo Achillis in such cases as those mentioned above. Its advantages are quite evident. The limb can be treated in the most favorable and comfortable position, and the bones placed in the best position for union, thereby accelerating it and lessening the liability to shortening, protracted confinement to bed, and anchylosis.

\section{FRACTURE OF THE PATELLA.}

BY WILBUR P. MORGAN, M. D., BALTIMORE, MARYLAND.

March 30, 1876, I was called to see Mrs. McG. for the first time. She was a small, delicate woman, weighing about one hundred pounds, twenty-seven years old, married, and the mother of two children. She lived in a small street in a healthy location in this city. I found her sitting on a lounge, nervous and anxious, suffering from the effects of a fall. Loss of power of motion being complained of, I examined and found complete horizontal fracture of the right patella, the bone being neatly divided into two equal fragments. The fracture was caused by the knee striking the rim of a basket which stood in the way when she fell. I temporarily dressed the fracture by the application of laths, laterally and posteriorly, until the primary irritation and swelling subsided.

April 2d. Mrs. McG. remained upon the lounge until to-day, when I removed the primary bandage and applied the starched apparatus. I cut the binder's boards to fit perfectly the shape of the leg, and sufficiently long to extend from the instep to the upper third of the femur upon the inside and the trochanter upon the outside of the leg. The boards, thoroughly softened, were then adapted closely to the leg, care 